Eixo Temático: Desenvolvimento de Estratégias Didáticas

\title{
ET-07-003 \\ BIODIVERSIDADES DOS INSETOS: APLICAÇÃO DE AULAS PRÁTICAS COM ARMADILHAS MANUAIS PARA ALUNOS DE ESCOLA PÚBLICA
}

Adriana Aneilza Silva, Évora Damares Marques Xavier, Fredson Murilo da Silva, Letícia Ribeiro Arcanjo, Rafaella Nadja Soares da Silva, Risoaldo do Espirito Santo Barbosa

Centro de Ciências Biológicas da Universidade Federal de Pernambuco.

http://dx.doi.org/10.21472/congrebio2016.et-07-003

\section{RESUMO}

Os insetos atuais são geralmente pequenos e têm o corpo segmentado, protegido por um exoesqueleto rígido de um material conhecido como quitina. Coletar e preservar os insetos são a melhor maneira de aprender sobre eles. Eles podem ser coletados manualmente, por armadilhas manuais, ou por atrativos. Nosso estudo teve como objetivo demonstrar que através de armadilhas manuais e de baixo custo, os alunos de escolas públicas podem observar na prática a importância e a biodiversidade dos insetos. Para a realização das coletas foram utilizados quatro modelos de armadilhas: Armadilhas de queda; Rede entomológica; Bandeja amarela e rede de intersecção. Foram coletados 312 insetos nas armadilhas de queda, 24 insetos na armadilha de bandeja, 6 insetos na rede entomológica e nenhum inseto na rede de intersecção, totalizando 342 insetos. Aulas práticas de coleta de inseto servem para favorecer o caráter investigativo, onde os alunos serão motivados pela curiosidade do saber por que os insetos caem nas armadilhas e como eles são atraídos para as mesmas. Em uma aula prática de coleta ao inseto o professor pode abordar vários assuntos trazendo conhecimentos para os alunos como exemplo: trabalhar a grandeza das biodiversidades dos insetos, mostrar o quanto é importante manter a biodiversidade e qual a importância dos insetos.

Palavras-chave: Biodiversidades; Insetos; Aulas práticas.

\section{INTRODUÇÃO}

Biodiversidade é a variabilidade de organismos vivos de todas origens compreendendo também os sistemas terrestres, marinhos e aquático e o complexo ecológico de que fazem parte (FELIX, 2010). Os insetos possuem a maior classe no grupo dos animais, com maior sucesso no ambiente terrestre. Os insetos são o melhor exemplo para representar a biodiversidade porque o número de espécie, adaptações, sua biomassa e o impacto ecológico são incomparáveis a outro grupo animal. Os insetos podem ser encontrados em diversos lugares como: nas plantas, no solo, ambiente doméstico, nas frutas caídas do pé e em decomposição. Coletar e preservar os insetos são a melhor maneira de aprender sobre eles, podendo sua coleta ser feita manualmente, por armadilhas manuais, ou por meios atrativos.

\section{OBJETIVO}

Coletar insetos através de armadilhas manuais e de baixo custo, observando a importância e sua biodiversidade, de forma que essa prática possa ser realizada e conduzida por professores em aulas práticas nas escolas, de modo que o aluno possa desenvolver um caráter investigativo e a importância de manter a biodiversidades dos insetos. 


\section{METODOLOGIA}

Para a realização das coletas foram utilizados quatro modelos de armadilhas. Cada modelo foi escolhido pensando-se na diversidade de espécies coletadas e na relação custo/eficiência que as armadilhas possuem. Foram aplicadas Armadilhas de queda, Rede entomológica, Bandeja amarela e rede de intersecção. As coletas foram realizadas na Cidade de Camaragibe-PE. As coletas das armadilhas de queda, da rede de intersecção e da bandeja foram realizadas no intervalo de 72 horas após as instalações, e com a rede entomológica foram feitas três coletas. $\mathrm{O}$ experimento teve duração de 9 dias, sendo replicadas por três vezes.

- Armadilhas de Queda: Segundo (FREIRES, 2011) as armadilhas de queda são aquelas que capturam insetos, principalmente aqueles que habitam o solo. Para confecção das armadilhas foram utilizadas 12 garrafas pet, aproximadamente $15 \mathrm{~cm}$ de comprimento por $10 \mathrm{~cm}$ de diâmetro, partidas ao meio, contendo: uma solução de álcool 70\% (150 $\mathrm{ml}$ ). Foram realizadas 12 perfurações no solo dentro de uma escala de 10 metros de distância de uma para outra, e colocado as garrafas até que sua borda ficasse no mesmo nível que o solo, assegurando que nenhuma folha, graveto, pedra impedisse o caminho dos insetos impossibilitando sua captura.

- Armadilhas de Bandeja: A bandeja d'água de cor amarela é usada como uma armadilha atrativa que coleta insetos atraídos pela cor (MOURA, 2012).A bandeja amarela foi instalada em uma parte aérea no centro, e aos seus redores as armadilhas de quedas. Dentro da bandeja foram adicionados $300 \mathrm{ml}$ de água e bananas machucadas. A segunda instalação da bandeja foi com água, pão e cerveja. E na terceira instalação deixamos a bandeja apenas com água.

- Rede Entomológica: Também conhecida como puçá (CRUZ, 2009). Para confecção da rede foi utilizado um pincel rodo, uma rede de nylon e um cabo de madeira. Para a coleta ficamos posicionados próximosà bandeja amarela, onde passávamos a rede durante 10 minutos.

- Rede de interceptação: Esse tipo de rede é muito comum e é usado na captura de insetos voadores ou que pousam sobre a vegetação (RESENDE, 2008). Para confecção utilizamos uma rede de nylon de $1 \mathrm{~m}$ x $50 \mathrm{~cm}$, que foi amarrado com cordão em suas pontas e fixando-as as árvores, nessa rede foi adicionado frutas como a manga, e nas coletas posteriores o pão com cerveja pois são alimentos atrativos para os insetos.

\section{RESULTADOS E DISCUSSÃO}

Foram coletados 312 insetos nas armadilhas de queda, 24 insetos na armadilha de bandeja, 6 insetos na rede entomológica e nenhuminseto na rede de intersecção. Totalizando 342 insetos, demonstrando uma grande biodiversidade de insetos na região.

As práticas foram pensadas para possibilitar, através das atividades práticas e pedagógicas a promoção da aprendizagem. Abrangendo todas as dimensões educativas como a criatividade e imaginação porque entender o predomínio de práticas bem-sucedidas nos remete à retomada das questões levantadas pela literatura, que elenca os temas do saber e do saber fazer e seus atores docentes e alunos (NEVES, 2011). Acreditamos que as aulas de ciências e biologia não precisam ser desenvolvidas somente na sala de aula, e que fazer uma prática do conteúdo ministrado irá contribuir para a construção do conhecimentopelo aluno e essa prática pode acontecer em qualquer lugar onde a escola tenha dominância, atuando no aprendizado integrado às outras disciplinas. Usar a interdisciplinaridade é possível nas aulas de ciências, os professores podem trabalhar a prática com a teoria, desenvolvendo as inteligências múltiplas e a 
participação efetiva dos alunos no processo pedagógico. É de grande importância práticas dentro e fora da sala de aula, proporcionando uma forma de aprendizagem mais agradável e ajudando no desenvolvimento de várias áreas importantes na vida de um indivíduo.

Compreendemos que cada metodologia aplicada deve ser planejada observando as características sociais, culturais e cognitivas aluno, respeitando a identidade de cada um. Segundo BRAZIL (2008) o planejamento das atividades práticas deve ser acompanhado por uma profunda reflexão não apenas sobre sua pertinência pedagógica, como também sobre os riscos reais ou potenciais a integridade física do estudante. Em nosso estudo, os materiais utilizados foram de baixo custo e de fácil manuseio, porém o professor precisa ficar atento para que os alunos não se machuquem com os materiais utilizados como, por exemplo, na hora de cavar as armadilhas de quedas, para que não sejam picados, e não peguem o inseto vivo ou mesmo matando o inseto, por isso utilizamos o álcool para matar os mesmos e os permanecer conservados. A atividade pratica com intuito investigativo não é muito utilizada nas escolas devido sua infraestrutura, mas como essa pratica que trabalhamos precisar apenas de um ambiente natural, ela pode ser feita até no jardim da escola ou uma saída de campo. Aulas práticas de coleta de inseto servem para favorecer o caráter investigativo, onde serão motivados pela curiosidade do saber por que os insetos caem nas armadilhas e como eles são atraídos para as mesmas. Em uma aula prática de coleta ao inseto o professor pode abordar vários assuntos trazendo conhecimentos para os alunos como exemplo: trabalhar a grandeza da biodiversidade dos insetos, mostrar o quanto é importante manter a biodiversidade, qual é a importância dos insetos, enfatizando que eles são responsável pelo equilíbrio do planeta sendo responsável por adubar a terra, pela reprodução de animais e vegetais e também o quantos eles podem sem prejudicial ao meio ambiente danificando plantações. É importante fazer com que os alunos identifiquem problemas ao seu entorno, estimulando a participarem de todo momento da aula.

\section{CONCLUSÃO}

Ao termino dessa atividade, acreditamos que ela pode proporcionarum papel fundamental na construção do conhecimento de cada aluno e de conceitos construídos por nós,futuros professores,nos induzindo sempre aatualizar e ajustar nossas aulas, buscando sempreestratégias que favoreçam a construção do conhecimento por parte dos alunos. Além disso, ações como essa pode fazer com que os alunos entendam que aprender pode tornar-se tão divertido quanto praticar, e, nesse caso, praticar torna-se interessante para o aluno e passa a fazer parte de sua lista de preferências.

\section{REFERÊNCIAS}

BRASIL. Secretaria da Educação Fundamental. Parâmetros Curriculares Nacionais: Ciências Naturais. Secretaria de Educação Fundamental. Brasília: MEC/SEF, 1998.

FÉLIX, M; ALMEIDA, C. E; FREIRE, N. M. S.; COSTA, J. Insetos: uma aventura pela Biodiversidade. Rio de Janeiro: Fundação Oswaldo Cruz, 2010.

MOURA, E. S.; AZEVEDO, F. R. A.; SANTOS, C. A. M.; NERE, D. R.; AZEVEDO, A. Bandeja d'água de cor amarela na captura de insetos em ecossistemas da Apararipe. 2012.

NEVES, M.A.S.C; Práticas educativas de relevância no processo de ensino aprendizagens em escola pública. Presidente Prudente, 2011,

RESENDE, D. L. M. C. Métodos usuais de coleta de insetos em ambientes lênticos. 2008. 